\title{
Bone Healing in Extraction Sockets Covered With Collagen Membrane Alone or Associated With Porcine-Derived Bone Graft: a Comparative Histological and Histomorphometric Analysis
}

\section{Renzo Guarnieri ${ }^{1}$, Luca Testarelli ${ }^{1}$, Luigi Stefanelli ${ }^{1}$, Francesca De Angelis ${ }^{1}$, Francesca Mencio ${ }^{1}$, Giorgio Pompa ${ }^{1}$, Stefano Di Carlo ${ }^{1}$}

${ }^{1}$ Department of Dental and Maxillofacial Sciences, School of Dentistry, University La Sapienza, Rome, Italy.

\author{
Corresponding Author: \\ Renzo Guarnieri \\ Via L. Cattarin, 3D, 31100 Treviso TV \\ Italy \\ E-mail: renzoguarnieri@gmail.com
}

\begin{abstract}
Objectives: The present paper reports data of a randomized study aimed to analyse and compare the histologic and histomorphometric aspects of bone healing in extraction sites covered with collagen membrane alone or associated with porcine-derived bone graft.

Material and Methods: Thirty patients, with single extraction sockets without severe bone wall defects in the premolar/molar region, were included. Ten extraction sockets were grafted with porcine-derived bone and covered with collagen membrane (group 1), 10 sites were covered with collagen membrane alone (group 2), and 10 sites healed spontaneously (group 3). After 4 months of healing, 26 ( 8 in group 1, 9 in group 2, and 9 in group 3) bone core specimens were harvested for histologic evaluation, then dental implants were placed.

Results: Sites in the group 1 and in the group 2 showed similar histologic and histomorphometric results without significantly differences in the percentage of vital bone (57.43\% [SD 4.8] vs. 60.01\% [SD 3.2]), and non-mineralized connective tissue $22.99 \%$ (SD 5.3) vs. $18.53 \%$ (SD 6.2). In group 1 a $16.57 \%$ (SD 3.8) of residual material was found.

Conclusions: Results showed that the use of collagen membrane alone or associated to porcine-derived bone improves the healing bone process compared to that of extraction sites spontaneously healed. Moreover, histomorphometric data related to bone quality, indicated that extraction sites without severe walls defects and with a vestibular bone thickness $>1.5 \mathrm{~mm}$, treated with a low resorbtion rate collagen membrane alone, do not need more than 4 months for dental implant insertion.
\end{abstract}

Keywords: alveolar resorption; artificial membranes; biocompatible materials; bone regeneration; bone substitutes; extraction socket.

Accepted for publication: 30 December 2017

To cite this article:

Guarnieri R, Testarelli L, Stefanelli K, De Angelis F, Mencio F, Pompa G, Di Carlo S.

Bone Healing in Extraction Sockets Covered With Collagen Membrane Alone or Associated With Porcine-Derived Bone Graft: a Comparative Histological and Histomorphometric Analysis

J Oral Maxillofac Res 2017;8(4):e4

URL: http://www.ejomr.org/JOMR/archives/2017/4/e4/v8n4e4.pdf

doi: $10.5037 /$ jomr.2017.8404 


\section{INTRODUCTION}

Studies on animal models and on humans have demonstrated that, following tooth extraction, the alveolar socket walls undergo a physiological resorbtion and remodelling process that results in a variable reduction of their dimensions $[1,2]$. To counteract the post-extraction alveolar volume loss, different socket preservation techniques have been proposed. [3-10]. All techniques consist to fill the resulting alveolar socket with different grafting materials with and without sealing the socket with absorbable or non-absorbable membranes [1114]. Grafting biomaterials have shown to provide better mechanical support during the healing and remodelling phase compared to spontaneous healing. Moreover, based on their osteogenic, osteoconductive, or osteoinductive properties, graft materials act as stimulants or scaffolds for bone growth. To avoid harvesting an autograft, and thereby eliminating additional surgical procedures, xenogenic bone has become a widely used biomaterial in socket preservation techniques, and has been supported by a number of publications $[\underline{9}, \underline{10}]$. Nevertheless, controversy remains whether xenogenic bone is truly resorbable, and whether the presence of residual graft particles could interfere with the healing process. Since most of the alveolar bone resorption occurs during the first 3 months of healing [1,2] , it is likely that the use of resorbable membranes alone might improve normal wound healing in extraction sites, if the membranes have enough stiffness, space making properties, and a low resorbtion rate. Recently, it has been proposed to clinicians a porcine-derived collagen membrane that in in vitro analysis [15] showed an initial rate of resorbtion of 12/16 weeks, and, compared to bovine-derived collagen membrane, a higher stretching resistance. Therefore, the present histological study aimed to compare histologically and histomorphometrically the effectiveness of socket preservation techniques using a slow resorption porcine-derived collagen membrane alone, or associated with porcine-derived bone. Clinical results of the present randomized study were previously reported by the same authors [16].

\section{MATERIAL AND METHODS}

Thirty patients, requiring extraction of a single premolar or molar tooth, who were interested in receiving a dental implant, were enrolled in the study between September 2016 and December
2016. Extraction sites to be regenerated were treated with a porcine-derived resorbable collagen-based membrane alone with an estimated resorbtion time of 12 - 14 weeks (Mem-Lok Pliable ${ }^{\circledR}$, BioHorizons, Birmingham, Al, USA), or with a porcine-derived resorbable collagen-based membrane associated to a highly porous anorganic porcine-derived bone mineral matrix with a particle size between 250 and $1000 \mu \mathrm{m}$ (MinerOss XP, BioHorizons, Birmingham, Al, USA). Criteria for inclusion in the study were:

- Age $\geq 18$ years;

- Good general health, no pregnancy, no uncontrolled metabolic disorders;

- Adequate restorative space for implant-retained restoration;

- At least $10 \mathrm{~mm}$ alveolar bone height without impingement on the maxillary sinus or mandibular canal, detected by intraoral radiographies or cone beam computed tomography (CBCT) scans.

Exclusion criteria were:

- History of systemic diseases that contraindicate oral surgery;

- Long-term non-steroidal anti-inflammatory drug therapy;

- Oral bisphosphonate therapy;

- Pregnancy or lactation;

- Unwillingness to return for the follow-up examinations;

- Cigarette consumption > 10 per day;

- Absence of vestibular or lingual socket wall, or $>50 \%$ missing vestibular/lingual socket wall, detected before surgery by intraoral radiographies and $\mathrm{CBCT}$ scans or during the extractive surgery using a graded periodontal probe (CP $15 \mathrm{UNC}$, HU-Friedy, Chicago, USA).

For further details regarding study population, recruitment, materials and methods, surgical procedures and assessed clinical parameters, see Guarneri et al. [16]. Patients were divided into three groups of 10 subjects each:

- Group 1: extraction sockets grafted with porcinederived bone, and covered with collagen membrane.

- Group 2: extraction sockets covered with collagen membrane alone.

- Group 3: extraction sockets with spontaneous healing.

The allocation in the group 1,2, and 3, was randomly assigned to each patient by computer- generated random number table. The randomization codes were stored in password-protected portable computers and enclosed in sequentially numbered, identical, opaque, sealed envelopes. The envelopes were opened in numerical order after tooth extraction. A third operator 
not involved in enrolment or treatment of patients performed data collection. The study had been approved by the Ethical Committee of University (Ref. No. 4597).

\section{Histologic analysis}

Bone specimens approximately $8 \mathrm{~mm}$ in length (8 in group 1, 9 in group 2, and 9 in group 3) were harvested 4 months following grafting procedures, during implant placement surgeries, by means of a trephine drill with a $2.5 \mathrm{~mm}$ internal diameter. They were immediately fixed in $10 \%$ buffered formalin and embedded in a glycolmethacrylate resin. After polymerization, specimens were sectioned along their longitudinal axes to a thickness of 70 microns (plastic Microtome, RM 2265). Slides were stained with Trichromic, and Methylene Blue/Basic Fuschin, and examined using an Olympus B51 microscope (Olympus America, Lake Success, NY, USA). The core area of every section $\left(0.1 \mathrm{~mm}^{2}\right)$ was chosen for histomorphometric analysis and area fraction percentage of each component in each section was measured automatically using Bioquant ${ }^{\circledR}$ image analysis software (R\&M Biometrics, Nashville, TN, USA) and images were captured with a Q-Imaging camera, 32-0013B-157, RETIGA, Colour 12bit. To evaluate bone quality, histomorphometric measurements were recorded according to the nomenclature approved by the American Society of Bone and Mineral Research, and analysed by a blinded researcher using Ky Plot 2.0 software, Informer Technologies, Inc. NY, USA.

\section{Statistical analysis}

Mean values and standard deviations (M [SD]) were calculated for each parameter. Groups were compared using a nonparametric Mann-Whitney U test for unpaired data. All statistical comparisons were conducted at $\mathrm{P}<0.05$ level of significance.

Table 1. Demographic data and dependent variables reported for the three experimental groups

\begin{tabular}{l|c|c|c}
\hline $\begin{array}{l}\text { Demographics and } \\
\text { dependent variables }\end{array}$ & Group 1 & Group 2 & Group 3 \\
\hline Patient (n) & 8 & 9 & 9 \\
\hline Age (years) & $20-63$ & $19-60$ & $21-56$ \\
\hline Sex (male/female) & $6 / 2$ & $3 / 6$ & $5 / 4$ \\
\hline Premolar/molar & $4 / 4$ & $6 / 3$ & $4 / 5$ \\
\hline Smoking habit (yes/no) & $3 / 5$ & $3 / 6$ & $2 / 7$ \\
\hline
\end{tabular}

$\mathrm{n}=$ number; Group 1 = porcine-derived graft material associated with collagen membrane; Group 2 = porcine-derived collagen membrane alone; Group $3=$ spontaneous healing.

\section{RESULTS}

Thirty patients were screened for this study. Four patients were excluded due to vestibular dehiscence greater than $50 \%$ of the length of the vestibular socket wall detected during the extractive surgery by means of a periodontal graded probe. A total of 26 patients (14 males and 12 females with an average age of 46.7 , ranging from 20 to 63 years) were allocated to the study groups of the trial. Eight patients were in the group 1, and 8 and 9 patients were in the group 2 and 3, respectively. At the end of the survey, 26 bone specimens were harvested and 26 dental implants (Laser-Lok Tapered, BioHorizons, Birmingham, Al, USA) were placed. Demographics and dependent variables for the three independent groups are reported in Table 1.

Morphological analysis showed normal trabecular bone structures without evident inflammatory infiltrates in groups 1 and 2. Group 1 showed the highest number of osteoids at different stages of mineralization (Figure 1 and 2). Group 2 showed mature trabecular bone organization, with limited presence of osteoid matrices and connective tissues (Figure 3 and 4). Group 3 had abundant presence woven bone, and connective tissues surrounding thin trabecular organizations (Figure 5 and 6 ).

Table 2 presents the histomorphometric comparative data of the three experimental groups. Histomorphometrically, in the spontaneously healed sockets, the percentage of newly formed bone was 48.85 (2.3), and the percentage of connective tissue was $34.17(4.1)$.

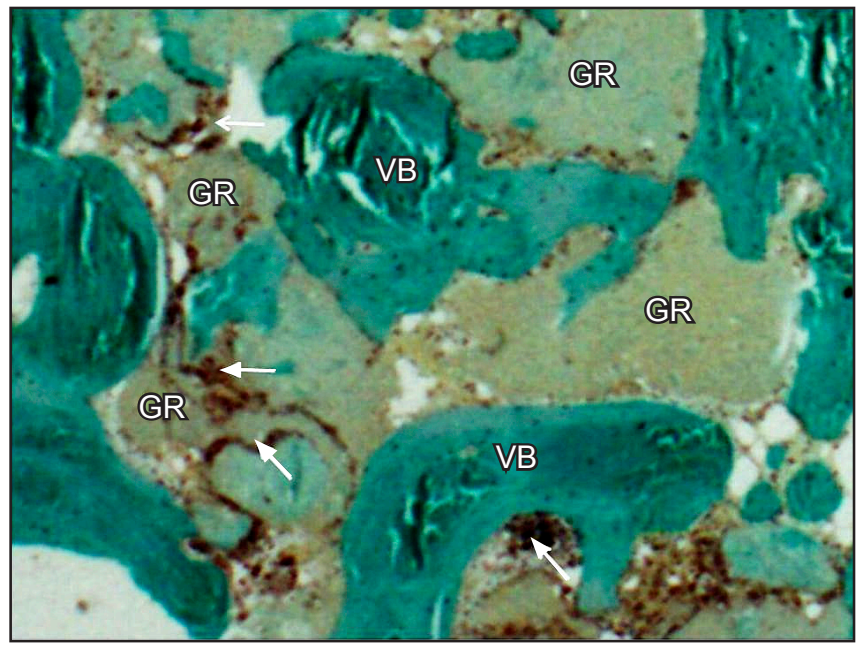

Figure 1. Histological micrograph of extraction socket treated with collagen membrane and porcine derived-bone (trichrome stain, original magnification x50). Residual porcine bone particles (GR) surrounded by vital bone (VB) in a remodelling process. Arrows indicate the osteoid tissue. 


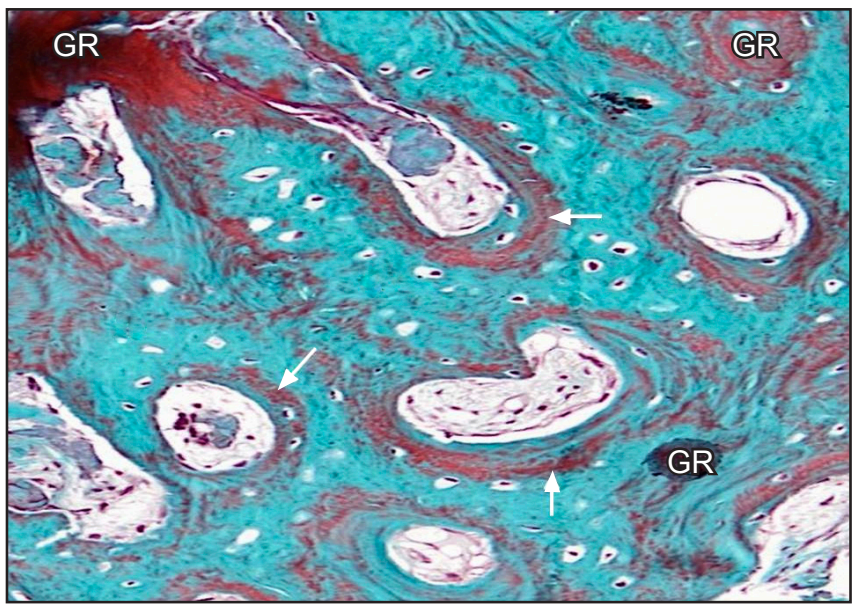

Figure 2. Histological micrograph of extraction socket treated with collagen membrane and porcine derived-bone (Masson's trichrome stain, original magnification x20). Porcine bone particles (GR) surrounded by immature bone in a remodelling process. Arrows indicate the osteoid tissue.

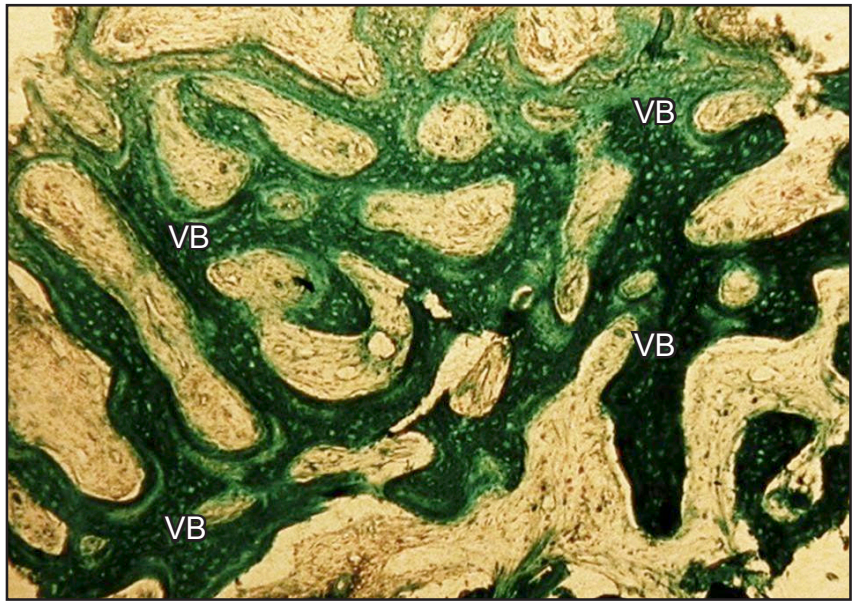

Figure 3. Histological micrograph of extraction socket treated with collagen membrane alone (trichrome stain, original magnification $\mathrm{x} 20$ ). Presence of vital bone (VB) with mature trabecular organization.

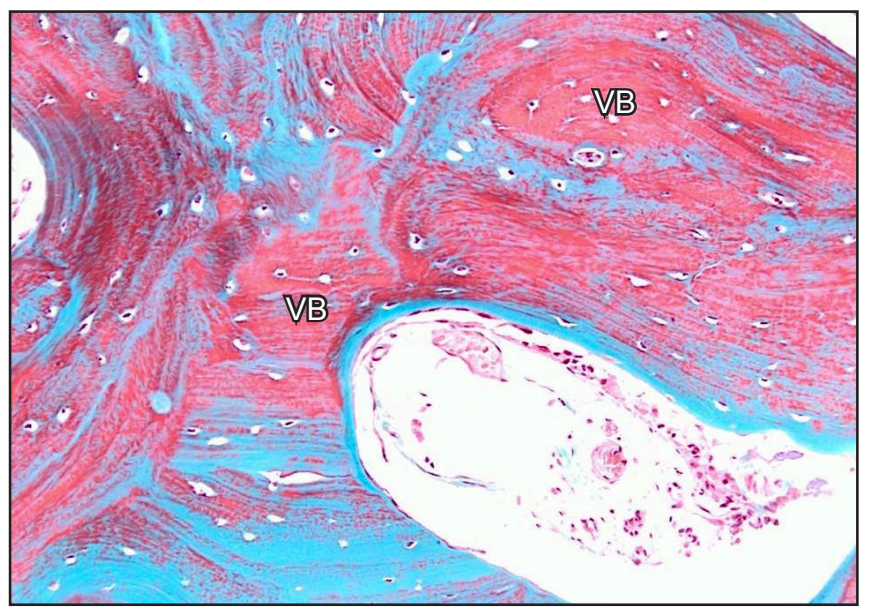

Figure 4. Histological micrograph of extraction socket treated with collagen membrane alone (Masson's trichrome stain, original magnification $\mathrm{x} 50$ ). Presence of vital bone (VB) with mature trabecular organization.

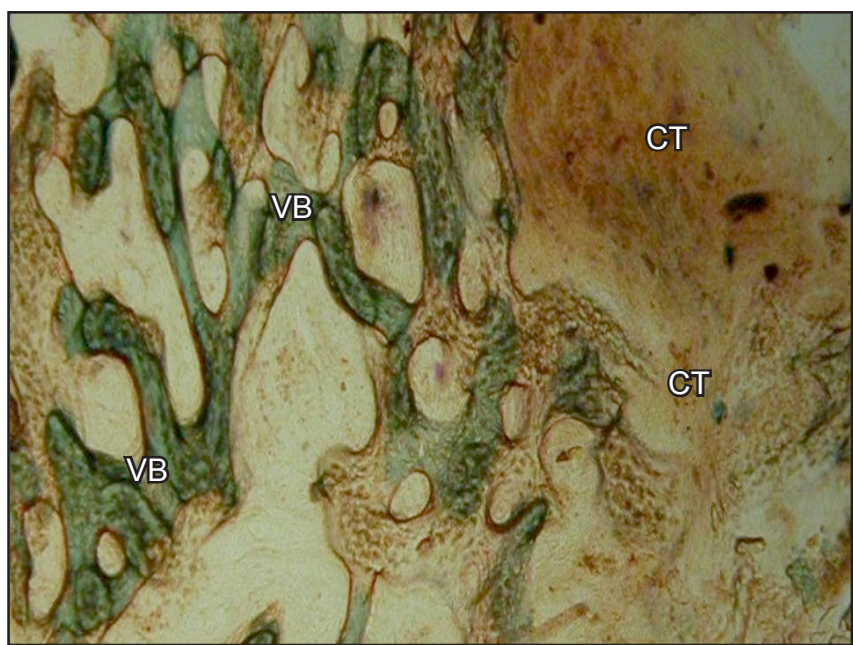

Figure 5. Histological micrograph of extraction socket spontaneously healed (trichrome stain, original magnification x20). Presence of vital bone (VB) with thin trabecular organisation surrounded by connective tissues (CT).

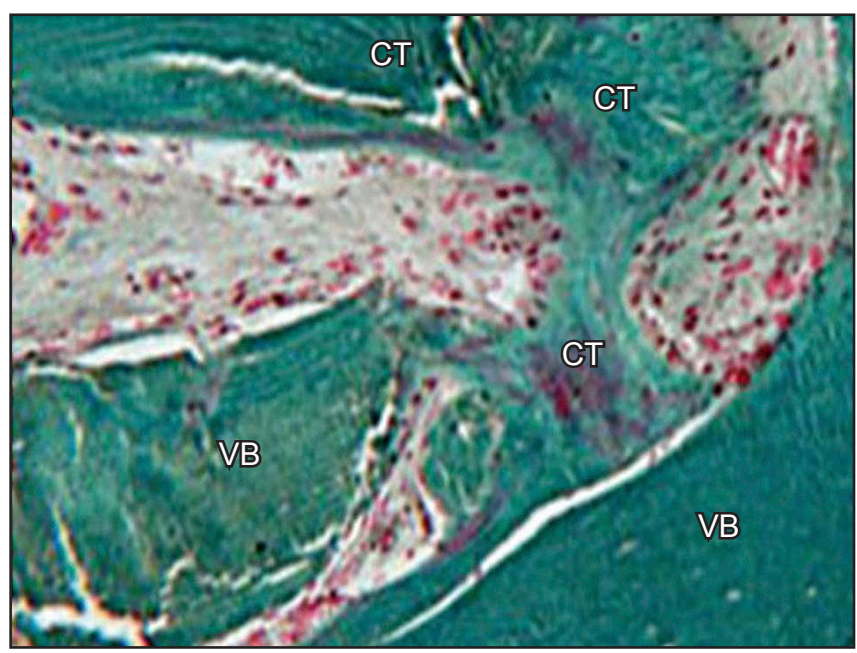

Figure 6. Histological micrograph of extraction socket spontaneously healed (Masson's trichrome stain, original magnification x50). Vital Bone (VB) with abundant presence of connective tissues (CT).

In sites treated with the membrane-alone, the percentage of newly formed bone was 60.01 (3.2), and the percentage of connective tissue was 18.53 (6.2), while in membrane and porcine xenograft sites, newly formed bone represented $57.43(4.8) \%$, and non-mineralized connective tissue 22.99 (5.3)\%. Differences between spontaneously healed sockets and treated sockets were statistically significant $(\mathrm{P}>0.05)$, while differences between sockets treated with membrane alone and membrane and xenograft were non statistically significant. In sites treated with membrane and xenogenic bone the percentage of residual graft material was 16.57 (3.8). In addition, these sites showed higher percentage of osteoid tissue/area compared to spontaneously healed sockets and sockets treated with membrane alone. 
Table 2. Histomorphometric analysis

\begin{tabular}{|c|c|c|c|c|}
\hline & Group 1 & Group 2 & Group 3 & Significance, \\
\hline & Mean (SD) & Mean (SD) & Mean (SD) & $\mathbf{P}<\mathbf{0 . 0 5}$ \\
\hline Tt. tissue area $\left(\mathrm{mm}^{2}\right)$ & $14.23(3.3)$ & $11.39(2.9)$ & $12.28(2.1)$ & - \\
\hline Tt. area of bone $\left(\mathrm{mm}^{2}\right)$ & $6.708(0.3)$ & $7.061(0.5)$ & $6.942(0.7)$ & - \\
\hline Tt. area of bone graft $\left(\mathrm{mm}^{2}\right)$ & $2.506(0.6)$ & 0 & 0 & - \\
\hline$\%$ connective tissue/Tt. area & $22.99(5.3)$ & $18.53(6.2)$ & $34.17(4.1)$ & 3 vs $2 / 1$ \\
\hline$\%$ bone/Tt. tissue area & $57.43(4.8)$ & $60.01(3.2)$ & $48.85(2.37)$ & 3 vs $2 / 1$ \\
\hline$\%$ graft $/$ Tt. tissue area & $16.57(3.8)$ & 0 & 0 & - \\
\hline Tt. osteoid area $\left(\mathrm{mm}^{2}\right)$ & $0.568(0.4)$ & $0.312(0.2)$ & $0.284(0.4)$ & $3 / 2$ vs 1 \\
\hline Tt. connective tissue area $\left(\mathrm{mm}^{2}\right)$ & $0.703(0.1)$ & $0.871(0.4)$ & $3.943(0.2)$ & 3 vs $2 / 1$ \\
\hline Tt. bone marrow area $\left(\mathrm{mm}^{2}\right)$ & $2.048(0.2)$ & $2.265(0.2)$ & $2.134(0.3)$ & - \\
\hline Tt. bone surface (mm) & $92.9(9.8)$ & $82.95(8.3)$ & $89.76(9.7)$ & - \\
\hline Tt. osteoid surface $(\mathrm{mm})$ & $25.94(3.6)$ & $11.71(2.4)$ & $9.58(1.7)$ & $3 / 2$ vs 1 \\
\hline$\%$ osteoid/Tt. bone surface & $21.62(2.9)$ & $12.06(2.7)$ & $10.23(2.1)$ & 3 vs $2 / 1$ \\
\hline Trabecular thickness (um) & $170.3(14.5)$ & $181.8(15.9)$ & $142.4(11.4)$ & 3 vs $2 / 1$ \\
\hline Trabecular number $\left(\mathrm{mm}^{-1}\right)$ & $3.64(1.1)$ & $4.21(1.4)$ & $3.89(0.6)$ & - \\
\hline Trabecular space (um) & $125.5(12.5)$ & $124.3(11.9)$ & $112.7(14.8)$ & 3 vs $2 / 1$ \\
\hline$\%$ inflammatory cells/Tt. tissue area & 1 & 1 & 1 & - \\
\hline
\end{tabular}

$\mathrm{SD}=$ standard deviation; $\mathrm{Tt} .=$ total biopsy core.

Group 1, treated with graft and membrane; Group 2, treated with membrane alone; Group 3, spontaneously healed.

\section{DISCUSSION}

The present study complements the previously published clinical study [16] on extraction socket preservation techniques by reporting on the histologic and histomorphometric outcomes. Results showed that the use of collagen membrane alone or associated to porcine-derived bone improves the healing bone process, compared to that of extraction sites spontaneously healed. These outcomes are in agreement with data reported by other studies $[\underline{17}, \underline{18}]$, and confirm that porcine-derived bone and reabsorbable membrane are effective in maintaining the post-extractive ridge volume, compared to spontaneously healed extraction sites. As previously reported [16] the comparative clinical results between the three experimental groups, showed that at 4 months re-entry surgery, extraction sockets without severe walls deficiencies and with vestibular bone thickness $\geq 1.5 \mathrm{~mm}$, grafted with porcine-derived bone and/or covered by collagen membrane have significantly lower vertical and horizontal bone changes compared to extraction sockets left to heal spontaneously. In addition, in type 1 premolar extraction sockets, based on Juodzbalys et al. classification [19], with vestibular bone thickness $\geq 1.5 \mathrm{~mm}$, the use of collagen membrane alone showed similar clinical results to the use of collagen membrane combined with bone graft. Outcomes of the present histological and histomorphometric investigation confirmed the reported clinical data, and indicated that a collagen membrane with low rate of resorbtion (12/14 weeks) may be used alone in extraction socket preservation procedures of sites without severe wall defects, and with a vestibular bone thickness $>1.5 \mathrm{~mm}$. The bone biopsies harvested from these sites revealed a percentage of bone/total tissue area of $60.01 \%$, a mean trabecular thickness of $181.8(15.9) \mu \mathrm{m}$, and a mean trabecular number of 4.21 (1.4) for $\mathrm{mm}^{-1}$. This result could be linked to physical and chemical features of the collagen membrane used in the present study which, in vitro analysis [15] showed to be characterized by a rate of resorbtion of 12/14 weeks at the intraoral implantation site, eliciting a low inflammatory and foreign body giant cell response. Moreover, the same collagen membrane showed significantly higher average suture pull out strength, and higher stability compared to conventional collagen membrane, that have been shown to correlate to a higher level of intermolecular crosslinking. Accordingly, it is possible hypothesized that the high stability and the low resorbtion rate may provide the membrane sufficient stiffness and space making properties, and the low degree of inflammation and foreign body response may result in enhanced tissue integration, improving the wound healing. 
Extraction sockets spontaneously healed, at the same re-entry time, showed a lower percentage of bone/total tissue area $(48.85 \%)$, of mean trabecular thickness $142.4(11.4) \mathrm{mm}$, and of mean trabecular number $3.89(0.6)$ for $\mathrm{mm}^{-1}$, with a greater amount of osteoid matrix, woven bone, and connective tissue. Based on comparative histological outcomes, it might be argued that in extraction sites without severe walls defects and with a vestibular bone thickness $>1.5 \mathrm{~mm}$, treats with a collagen membrane with low resorbtion rate, is unnecessary to wait over 4 months prior to dental implant insertion. Compared to sites treated with collagen membrane alone, extraction sites treated with porcine-derived bone and collagen membrane, showed at 4 months re-entry surgery a similar percentage of newly formed bone, of mean trabecular thickness, and of mean trabecular number, but also the presence of a $16.57(3.8) \%$ of residual graft material. Despite the presence of these residual graft particles, at the moment of the implant placement, after 4 months, these sites did not provide clinically the tactile sensation of drilling into "better" quality bone or "poorer" quality bone compared to sites without residual graft material.

The absence of inflammatory cells or foreign body reaction found in sites grafted with porcinederived bone, indicates that this biomaterial is osteoconductive, and acts as a natural scaffold for new bone formation. However, the presence of abundant osteoid tissue, mostly distributed around the residual graft granules, and the presence of active resorbtion signs and areas of bone apposition on residual graft particles, suggest, albeit indirectly, that the resorbtion and remodelling process could continue in later times, and could delay the healing process. The final goal of any grafting procedure should be the achievement of $100 \%$ living bone and reactive tissue able to undergo a sustained state of remodelling. Moreover, the ideal graft material should be able not only to minimize the ridge remodelling, but also to promote bone formation as fast as possible to shorten the treatment time. The degree of resorbtion of the graft biomaterials has been related to several factors, among which the pore size, the pore morphology, the pore percentage, the connection between pores, the granulometry, and the interconnectivity [20-25]. These factors influence both the possibility that a greater number of osteoblasts can penetrate the porous structure, both the degree of angiogenesis and the resulting flux of nutrient and of oxygen. Moreover they could also affect the level of intimacy between osteoblastic cells and the graft particles. The porcine-derived bone used in the present study is characterized by an average pore size of $474.26(76.2) \mu \mathrm{m}$, by a trabecular thickness of $121.76(21.9) \mu \mathrm{m}$, and by a pore connectivity of $88-95 \%$, which are similar to those of human bone [26]. These features might explain the high resorbtion rate $(83.43 \%)$ of the porcine-derived bone founded in the present study. However, to date, controversy still remains, whether the porcine-derived bone is completely reabsorbable [27]. Non-resorbtion might not only result in shielding of the newly formed bone from physiological stresses necessary for further remodelling and maturation, but the presence of residual graft particles could also influence or interference with osseointegration process of dental implants, and bone-to-implant contact [28,29]. Moreover, as suggested by other authors, granules around the dental implant body could represent a locus minoris resistentiae in case of peri-implant infection [30]. Contradictory considerations are reported in literature on the "biological meaning" of residual graft particles present in biopsy samples harvested from regenerated extraction sockets. Highlighting that the almost complete incorporation of the residual graft particles in bone creates a dense and hard tissue network with particles completely surrounded by vital bone, some authors $[\underline{17}, \underline{18}]$ suggested that, once the biomaterial particles are embedded in mineralized bone, they acted similarly to the host bone, providing a similar biologic support. On the contrary, other authors $[\underline{31}, \underline{32}]$ having identified the presence of multinucleated cells and of osteoclastic activity around xenogenic bone residual particles suggested that these may influence the remodelling process and delay the socket healing. In order to draw conclusions, more histological studies are necessary, especially monitoring the long term results of the implants inserted in regenerated extraction sites.

This histological and histomorphometric study raises some questions: how much vital bone and what degree of bone maturation, are needed to support a dental implant during healing? Will sites grafted with porcine-derived bone in time "catch up" and have a higher percentage of vital bone after the residual particles have been broken down and replaced, or these sites will have a higher risk of implant failure if the residual graft particles will remain in situ? Further research in these areas is needed to determine the clinical significance of these findings.

\section{CONCLUSIONS}

Within the limits of the present study, histologic and histomorphometric results showed that the use of collagen membrane alone or associated to porcine- 
derived bone improves the healing bone process compared to that of extraction sites spontaneously healed. Moreover, they showed that there are not significantly differences in the percentage of vital bone, mean trabecular thickness and mean trabecular number in extraction sockets without severe wall defects and with a vestibular bone thickness $>1.5$ $\mathrm{mm}$, treated with a low resorbtion rate collagen membrane alone, versus sites treated with membrane plus porcine-derived bone. However, these sites did show a significantly greater presence of osteoid tissue, mostly distributed around residual graft granules, indicating bone still in maturation phase. In accordance with histomorphometric data related to bone quality, results indicated that extraction sites without severe walls defects and with a vestibular bone thickness $>1.5 \mathrm{~mm}$, treated with a low resorbtion rate collagen membrane alone, do not need more than 4 months for dental implant insertion.

\section{ACKNOWLEDGMENTS AND DISCLOSURE STATEMENTS}

The authors report no conflicts of interest related to this study. The authors would like to thank Patricia DeVilliers for histological and histomorphometric evaluation. Materials to the study were provided by BioHorizons, Birmingham, Al, USA.

\section{REFERENCES}

1. Araújo MG, Lindhe J. Dimensional ridge alterations following tooth extraction. An experimental study in the dog. J Clin Periodontol. 2005 Feb;32(2):212-8. [Medline: 15691354] [doi: 10.1111/j.1600-051X.2005.00642.x]

2. Trombelli L, Farina R, Marzola A, Bozzi L, Liljenberg B, Lindhe J. Modeling and remodeling of human extraction sockets. J Clin Periodontol. 2008 Jul;35(7):630-9. [Medline: 18498382] [doi: 10.1111/j.1600-051X.2008.01246.x]

3. Araújo MG, Lindhe J. Ridge alterations following tooth extraction with and without flap elevation: an experimental study in the dog. Clin Oral Implants Res. 2009 Jun;20(6):545-9. [Medline: 19515033]

4. Araújo MG, Lindhe J. Ridge preservation with the use of Bio-Oss collagen: A 6-month study in the dog. Clin Oral Implants Res. 2009 May;20(5):433-40. [Medline: 19522974] [doi: 10.1111/j.1600-0501.2009.01705.x]

5. Araújo MG, Lindhe J. Socket grafting with the use of autologous bone: an experimental study in the dog. Clin Oral Implants Res. 2011 Jan;22(1):9-13. [Medline: 21091539] [doi: 10.1111/j.1600-0501.2010.01937.x]

6. Wang HL, Kiyonobu K, Neiva RF. Socket augmentation: rationale and technique. Implant Dent. 2004 Dec;13(4):286-96. [Medline: 15591989] [doi: 10.1097/01.id.0000148559.57890.86]

7. Wang HL, Tsao YP. Mineralized bone allograft-plug socket augmentation: rationale and technique. Implant Dent. 2007 Mar;16(1):33-41. [Medline: 17356370] [doi: 10.1097/ID.0b013e318031ece6]

8. Hämmerle $\mathrm{CH}$, Araújo MG, Simion M; Osteology Consensus Group 2011. Evidence-based knowledge on the biology and treatment of extraction sockets. Clin Oral Implants Res. 2012 Feb;23 Suppl 5:80-2. [Medline: 22211307] [doi: 10.1111/j.1600-0501.2011.02370.x]

9. Vignoletti F, Matesanz P, Rodrigo D, Figuero E, Martin C, Sanz M. Surgical protocols for ridge preservation after tooth extraction. A systematic review. Clin Oral Implants Res. 2012 Feb;23 Suppl 5:22-38. [Medline: 22211304] [doi: 10.1111/j.1600-0501.2011.02331.x]

10. Vittorini Orgeas G, Clementini M, De Risi V, de Sanctis M. Surgical techniques for alveolar socket preservation: a systematic review. Int J Oral Maxillofac Implants. 2013 Jul-Aug;28(4):1049-61. [Medline: 23869363] [doi: $10.11607 /$ jomi.2670]

11. Fickl S, Zuhr O, Wachtel H, Bolz W, Huerzeler M. Tissue alterations after tooth extraction with and without surgical trauma: a volumetric study in the beagle dog. J Clin Periodontol. 2008 Apr;35(4):356-63. [Medline: 18353082] [doi: 10.1111/j.1600-051X.2008.01209.x]

12. Fickl S, Zuhr O, Wachtel H, Stappert CF, Stein JM, Hürzeler MB. Dimensional changes of the alveolar ridge contour after different socket preservation techniques. J Clin Periodontol. 2008 Oct;35(10):906-13. [Medline: 18713258] [doi: 10.1111/j.1600-051X.2008.01305.x]

13. Fickl S, Zuhr O, Wachtel $\mathrm{H}$, Bolz W, Huerzeler MB. Hard tissue alterations after socket preservation: an experimental study in the beagle dog. Clin Oral Implants Res. 2008 Nov;19(11):1111-8. [Medline: 18983313] [doi: 10.1111/j.1600-0501.2008.01575.x]

14. Meloni SM, Tallarico M, Lolli FM, Deledda A, Pisano M, Jovanovic SA. Postextraction socket preservation using epithelial connective tissue graft vs porcine collagen matrix. 1-year results of a randomised controlled trial. Eur J Oral Implantol. 2015 Spring;8(1):39-48. [Medline: 25738178]

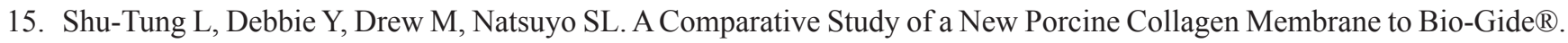
Science, Technology, Innovation 2015 Feb;1-5. [URL: https://www.osseonews.com] 
16. Guarnieri R, Stefanelli L, De Angelis F, Mencio F, Pompa G, Di Carlo S. Extraction Socket Preservation Using Porcine-Derived Collagen Membrane Alone or Associated with Porcine-Derived Bone. Clinical Results of Randomized Controlled Study. J Oral Maxillofac Res. 2017 Sep 30;8(3):e5. [Medline: 29142657] [PMC free article: 5676315] [doi: 10.5037/jomr.2017.8305]

17. Barone A, Aldini NN, Fini M, Giardino R, Calvo Guirado JL, Covani U. Xenograft versus extraction alone for ridge preservation after tooth removal: a clinical and histomorphometric study. J Periodontol. 2008 Aug;79(8):1370-7. [Medline: 18672985] [doi: 10.1902/jop.2008.070628]

18. Barone A, Toti P, Quaranta A, Alfonsi F, Cucchi A, Negri B, Di Felice R, Marchionni S, Calvo-Guirado JL, Covani U, Nannmark U. Clinical and Histological changes after ridge preservation with two xenografts: preliminary results from a multicentre randomized controlled clinical trial. J Clin Periodontol. 2017 Feb;44(2):204-214. [Medline: 27883211] [doi: $10.1111 /$ jepe.12655]

19. uodzbalys G, Sakavicius D, Wang HL. Classification of extraction sockets based upon soft and hard tissue components. J Periodontol. 2008 Mar;79(3):413-24. [Medline: 18315423] [doi: 10.1902/jop.2008.070397]

20. Hing KA, Best SM, Tanner KE, Bonfield W, Revell PA. Mediation of bone ingrowth in porous hydroxyapatite bone graft substitutes. J Biomed Mater Res A. 2004 Jan 1;68(1):187-200. [Medline: 14661264] [doi: 10.1002/jbm.a.10050]

21. van Blitterswijk CA, Grote JJ, Kuijpers W, Daems WT, de Groot K. Macropore tissue ingrowth: a quantitative and qualitative study on hydroxyapatite ceramic. Biomaterials. 1986 Mar;7(2):137-43. [Medline: 3011138] [doi: 10.1016/0142-9612(86)90071-2]

22. Wang W, Itoh S, Tanaka Y, Nagai A, Yamashita K. Comparison of enhancement of bone ingrowth into hydroxyapatite ceramics with highly and poorly interconnected pores by electrical polarization. Acta Biomater. 2009 Oct;5(8):3132-40. [Medline: 19426842] [doi: 10.1016/j.actbio.2009.04.036]

23. Yamada Y, Tamura T, Hariu K, Asano Y, Sato S, Ito K. Angiogenesis in newly augmented bone observed in rabbit calvarium using a titanium cap. Clin Oral Implants Res. 2008 Oct;19(10):1003-9. [Medline: 18828816] [doi: $10.1111 / \mathrm{j} .1600-0501.2008 .01554 . x$ ]

24. Motomiya M, Ito M, Takahata M, Kadoya K, Irie K, Abumi K, Minami A. Effect of Hydroxyapatite porous characteristics on healing outcomes in rabbit posterolateral spinal fusion model. Eur Spine J. 2007 Dec;16(12):2215-24. [Medline: 17891422] [PMC free article: 2140139] [doi: 10.1007/s00586-007-0501-0]

25. de Misquita MR, Bentini R, Goncalves F. The performance of bone tissue engineering scaffolds in in vivo animal models: A systematic review. J Biomater Appl. 2016 Nov;31(5):625-636. [Medline: 27334129] [doi: 10.1177/0885328216656476]

26. Parfitt AM, Drezner MK, Glorieux FH, Kanis JA, Malluche H, Meunier PJ, Ott SM, Recker RR. Bone histomorphometry: standardization of nomenclature, symbols, and units. Report of the ASBMR Histomorphometry Nomenclature Committee. J Bone Miner Res. 1987 Dec;2(6):595-610. [Medline: 3455637] [doi: 10.1002/jbmr.5650020617]

27. Becker W, Clokie C, Sennerby L, Urist MR, Becker BE. Histologic findings after implantation and evaluation of different grafting materials and titanium micro screws into extraction sockets: case reports. J Periodontol. 1998 Apr;69(4):414-21. [Medline: $\underline{9609370]}$ [doi: 10.1902/jop.1998.69.4.414]

28. Galindo-Moreno P, Hernández-Cortés P, Mesa F, Carranza N, Juodzbalys G, Aguilar M, O’Valle F. Slow resorption of anorganic bovine bone by osteoclasts in maxillary sinus augmentation. Clin Implant Dent Relat Res. 2013 Dec;15(6): 858-66. [Medline: 22376122] [doi: 10.1111/j.1708-8208.2012.00445.x]

29. Canullo L, Wiel Marin G, Tallarico M, Canciani E, Musto F, Dellavia C. Histological and Histomorphometrical Evaluation of Postextractive Sites Grafted with Mg-Enriched Nano-Hydroxyapatite: A Randomized Controlled Trial Comparing 4 Versus 12 Months of Healing. Clin Implant Dent Relat Res. 2016 Oct;18(5):973-983. [Medline: 26497643] [doi: $10.1111 /$ cid.12381]

30. Araújo M, Linder E, Wennström J, Lindhe J. The influence of Bio-Oss Collagen on healing of an extraction socket: an experimental study in the dog. Int J Periodontics Restorative Dent. 2008 Apr;28(2):123-35. [Medline: 18546808]

31. Araújo M, Linder E, Lindhe J. Effect of a xenograft on early bone formation in extraction sockets: an experimental study in dog. Clin Oral Implants Res. 2009 Jan;20(1):1-6. [Medline: 19126101] [doi: 10.1111/j.1600-0501.2008.01606.x]

32. Piattelli M, Favero GA, Scarano A, Orsini G, Piattelli A. Bone reactions to anorganic bovine bone (Bio-Oss) used in sinus augmentation procedures: a histologic long-term report of 20 cases in humans. Int J Oral Maxillofac Implants. 1999 NovDec;14(6):835-40. [Medline: 10612920] 


\section{To cite this article:}

Guarnieri R, Testarelli L, Stefanelli K, De Angelis F, Mencio F, Pompa G, Di Carlo S.

Bone Healing in Extraction Sockets Covered With Collagen Membrane Alone or Associated With Porcine-Derived Bone Graft: a Comparative Histological and Histomorphometric Analysis

J Oral Maxillofac Res 2017;8(4):e4

URL: http://www.ejomr.org/JOMR/archives/2017/4/e4/v8n4e4.pdf

doi: $\underline{10.5037 / j o m r .2017 .8404}$

Copyright (C) Guarnieri R, Testarelli L, Stefanelli K, De Angelis F, Mencio F, Pompa G, Di Carlo S. Published in the JOURNAL OF ORAL \& MAXILLOFACIAL RESEARCH (http://www.ejomr.org), 31 December 2017.

This is an open-access article, first published in the JOURNAL OF ORAL \& MAXILLOFACIAL RESEARCH, distributed under the terms of the Creative Commons Attribution-Noncommercial-No Derivative Works 3.0 Unported License, which permits unrestricted non-commercial use, distribution, and reproduction in any medium, provided the original work and is properly cited. The copyright, license information and link to the original publication on (http://www.ejomr.org) must be included. 